\title{
A auto-organização da vida como pressuposto para a compreensão da morte infantil
}

\author{
The life self-organization as a requirement \\ to understand the infancy death
}

Helena de Oliveira 1

Maria Cecília de Souza Minayo 2

\footnotetext{
1 Instituto Fernandes Figueira. Av. Rui Barbosa, 716 Flamengo - 22250-020 - Rio de Janeiro - RJ. helena-oliveira@bol.com.br 2 Centro Latino Americano de Estudos de Violência e Saúde Jorge Careli CLAVES. Av. Brasil, 4.365 Pavilhão Mourisco -

Manguinhos - 21045-900 Rio de Janeiro - RJ
}

\begin{abstract}
Considered as a health indicator traditionally valorised and recognised, infancy death is still a challenge for the Governments and institutions, both nationally and internationally, which are struggling to reduce those numbers. The causes of infancy death are linked, mainly, to pneumonia and gastro-enteritis pathologies that have a vicious circle that is enhanced and/or disseminated by under-nourishment. Searching for a less biological way and, in fact, more effective and efficient interventions, recent studies are being directed by social-economical factors as indicative of illness and death increase during the first year of life. Social class, mother's educational background, basic sewage system and family's income are some of the variables which can be attributed this differentiated risk. But an instigating question persists: considering families with similar social class, income and educational background, for instance, why some children die still in infancy and others do not? This questioning inspired this article that, from a self-organisation theory, search for a contribution to clarify the complex mechanisms related to death in the first year of life. We suppose that the family's dynamics, understood inside the concept of self-organisation, generates the conditions for increasing the risk of infancy death.

Key words Infant mortality, Families, Children, Risk factors
\end{abstract}

Resumo Indicador de saúde tradicionalmente valorizado e reconhecido, a mortalidade infantil é ainda um desafio para os governos e instituições nacionais e internacionais interessadas/envolvidas na luta pelo seu declínio. Suas causas estão ligadas basicamente às pneumonias e às gastroenterites; patologias que têm seu círculo vicioso agravado elou desencadeado pela desnutrição. Em busca de uma abordagem menos biológica, e no fundo de intervenções mais efetivas e eficazes, os estudos mais recentes têm sido direcionados aos fatores socioeconômicos que aumentariam o risco de doença e de morte no primeiro ano de vida. Classe social, escolaridade materna, saneamento básico e renda familiar são algumas das variáveis às quais se atribui esse risco diferenciado. Um instigante questionamento, entretanto, persiste: considerando famílias da mesma classe social, renda familiar e escolaridade materna, por exemplo, por que em algumas morrem crianças pequenas e em outras não? Esse questionamento inspirou este artigo que, a partir da teoria da auto-organização, busca contribuir para o elucidamento dos complexos mecanismos envolvidos na morte de crianças no primeiro ano de vida. Parte-se do pressuposto de que a dinâmica familiar, compreendida dentro do conceito de auto-organização, cria as condições para esse aumentado risco de mortalidade infantil.

Palavras-chave Mortalidade infantil, Familias, Crianças, Fatores de risco 


\section{Introdução}

Em geral nossa sociedade, aí incluída a categoria médica, tende a se recusar a tratar, como seu, o fenômeno da morte. Estranhá-lo, esquecê-lo, não nomeá-lo, apenas aceitá-lo como inevitável: eis a atitude mais comum e repetitiva em nosso cotidiano. No âmbito da medicina, menos que aceitar, o lema é estabelecer com a morte um duelo de poder, onde, quando ela é vencida, a onipotência médica se reproduz e se reafirma em seu objetivo essencial. Prova disso são todos os feitos mitológicos do setor que, não só atribuem ao médico o poder quase divino, mas levam a sociedade a reconhecê-lo apenas abaixo de Deus. São esses mesmos mitos que, do ponto de vista cultural, impulsionam as avançadas pesquisas de genética e de inibição e retardamento do envelhecimento. O sonho de imortalidade nunca foi tão vivido e revivido pela medicina e acariciado pela sociedade, como no momento presente, projetando-se como a grande utopia do século XXI.

Interessante que, enquanto as novas descobertas científicas e tecnológicas prometem, antes da metade deste século, quase dobrar a expectativa de vida, com a longevidade média tendendo a aumentar, a morte continua a rondar a sociedade nas bases das relações sociais, nas suas chamadas causas externas. Homicídios, suicídios, violências no trânsito, no trabalho, nos lares são formas atuais que a companheira da vida apresenta para assustar pretensos imortais. E assim, correndo contra todas as ameaças de dor e sofrimento, sobretudo correndo individualmente, o ser deste novo século percebe que a morte é apenas e simplesmente a outra banda da dialética da vida. E que natural, social e cultural ela está aí, tão unida e tão fortemente atada ao nascimento do qual é o próprio germe.

Este artigo tenta trazer para o setor saúde essa reflexão, ao discutir e problematizar bases filosóficas da teoria da auto-organização como potencializadoras de uma forma de compreensão da dinâmica da vida e da morte. E, ao focalizá-las, toma como centro essa questão no primeiro ano da infância, onde o precoce falecer parece estabelecer um paradoxo com as leis da natureza. Toda a discussão deste artigo se assenta na idéia da construção subjetiva da existência onde se entrelaçam três grandes sistemas, o biológico, o ecológico e o social.

\section{Do presente ao passado: a história ao reverso das representações da morte}

A interdição e a recusa da morte em nosso século são fenômenos inegáveis. Profissionalizada, medicalizada, sobretudo hospitalizada, a morte é desapropriada tanto do contexto do indivíduo e de sua família, quanto de seu meio social mais imediato. No âmbito da medicina, sua dimensão biológica suplanta todas as outras e sua tecnificação é crescente, o que dificulta sobremaneira a detecção do momento exato em que ocorre, transformando o falecimento, no mais das vezes, em um processo prolongadamente doloroso e solitário. Morre-se por descuido, por acidente; morre-se por desobediência às regras do bem-viver. Culpa-se o indivíduo e, no caso da criança pequena, a família, por seu adoecimento e - no fundo - pelo suposto fracasso que resultou em seu óbito.

As tentativas de ocultamento dos dolorosos momentos do falecimento, sobretudo às crianças; os cuidados com a (não) apresentação do cadáver; as cerimônias de enterro; em todas essas "tentativas" de rituais os momentos do morrer são abreviados, ocultados a mais não poder, numa tentativa de negar não só a morte em si, mas a morte como constitutiva da natureza de todos os seres vivos.

As atitudes frente à morte em nossa sociedade têm raízes na Revolução Industrial, no século XVIII, com a intensificação da cultura capitalista e a necessidade social, cada vez maior, de se transformar os corpos em objeto de produção. O poder médico começa a se insurgir contra o poder religioso, introduzindo a prática de dissecamento de cadáveres e se apropriando progressivamente da morte e dos mortos.

Muros são construídos em torno dos cemitérios e estes são mantidos com as portas fechadas e longe das cidades. Rompendo sua tradicional convivência com o mundo dos vivos, desde finais do século XVIII, a morte passa a ter um caráter extremamente dramático, com manifestações emocionais incontroláveis por parte dos parentes e amigos, que freqüentemente choram e gesticulam convulsivamente. Os mortos são lembrados com insistência pelos vivos, principalmente por meio da prática de construção de jazigos perpétuos e das visitas aos túmulos e cemitérios. O testamento se torna um ato legal de transmissão da herança.

Do século XII à Revolução Industrial, ao contrário, desenvolveu-se uma crença inaba- 
lável na existência após a morte, sendo esta a última prova à qual o indivíduo se submeteria para alcançar a vida. Presidido pelo poder religioso, o quarto do moribundo era o local e o templo do Julgamento Final. A noção de uma biografia humana que se prolongaria após a morte do corpo trazia então, na individualização das sepulturas, sua marca particular.

Antes disso, porém, na Baixa Idade Média, havia um laço contínuo e uma pacífica coexistência entre os vivos e os mortos, uma profunda familiaridade com a morte e o morrer e a certeza de que a mesma fazia parte de um destino coletivo da espécie humana. A relação entre morte e vida era não só sabida, mas vivida coletivamente com tranqüilidade, resignação e sem expressão religiosa, como as duas faces de um mesmo fenômeno. Os mortos eram enterrados dentro das cidades; os cemitérios eram o centro da vida social; os ossos serviam de elementos de decoração; o morrer constituía uma cerimônia pública, prolongada, presidida pelo moribundo, e contava sempre com a presença das crianças.

Essa concepção da morte era uma forma de aceitação da ordem da natureza, aceitação ao mesmo tempo ingênua na vida cotidiana e sábia nas especulações astrológicas (Ariés, 1988). E é curioso notar que todas as culturas (não capitalistas) acreditam que a morte comece antes da morte e que a vida dure depois da vida, de forma que morte e vida não sejam inconciliáveis, que uma não seja o fim da outra, que ambas se encontrem no mesmo plano e não sejam pensáveis separadamente (Rodrigues, 1983).

Para Morin (1980), existem dois mitos fundamentais presentes nas representações da morte através dos tempos e das culturas que, mesmo arcaicas, teimam em sobreviver de variadas formas nos dias de hoje: a morte-renascimento e a morte-duplo. A primeira simboliza a vida e a fecundação, aparecendo sob várias vertentes culturais: nos ritos de iniciação, de sacrifício e de canibalismo; nas analogias com a maternidade (lar, terra, retorno, água) e com o sono (a noite). A morteduplo simboliza a sobrevivência do morto, seja no além - por duplicação ou por outro nascimento - seja no aqui, por reencarnação. Ambas estão presentes não só na mentalidade arcaica, mas também no folclore, no ocultismo, nas artes, na mentalidade onírica, infantil, poética e filosófica. Daí seu caráter universal.
Segundo o autor, essas duas representações se confundem, sendo metáforas míticas dos processos biológicos fundamentais ligados à reprodução: a duplicação e a fecundação. São mitos que, apontando para uma continuidade para além da descontinuidade que a morte evidencia, acalmam o traumatismo da morte individual, fazendo que ela seja compensada pelo renascimento da espécie.

Parece a alguns autores que apenas os seres vivos mais evoluídos estão sujeitos à morte, não sendo esta uma propriedade inerente à substância vital. Os unicelulares podem se reproduzir indefinidamente por cissiparidade; numerosos animais e vegetais inferiores são, em princípio, amortais, pois possuem uma capacidade infinita de regeneração; nossas próprias células, se isoladas de nosso organismo, parecem ter uma duração indeterminada de vida (Morin, 1996). A mortalidade, para Morin, é o preço da organização e da especialização da vida - sinal, ao mesmo tempo, de sua potência adaptativa e da imensa fragilidade que essa adaptatividade lhe traz. Em outras palavras, parece que é na proximidade e na ameaça da morte que a vida encontra sua mais determinada fonte de invenção. Onde a vida quase desaparece - biológica e psiquicamente - daí emergem novas formas de existência, desafiando e enganando os poderes da mortalidade e da finitude.

Evoluir, portanto, organizar-se, especializar-se, diversificar-se e adaptar-se significa aceitar a metamorfose: a morte em favor de um nascimento, a morte-renascimento. A única maneira de superar a morte é integrá-la de certo modo à vida, (...) no mais íntimo dela mesma (Morin, 1996). Assumi-la como um risco permanente, como um encontro, uma fecundação da vida com o acaso. A morte nasce a cada salto para a frente da vida (Morin, 1996).

Se, desta maneira, a morte está indissociavelmente ligada à vida, se não há divórcio real entre a morte e a vida humana, poderíamos buscar nesta as raízes daquela. Mas, para isso, seria necessário não um saber sobre a morte - ainda que de qualquer natureza, seja antropológica, biomédica e filosófica - mas um saber sobre a vida: uma teoria da vida. É isso que se tenta ensaiar neste artigo, acompanhando as reflexões de vários campos do conhecimento que se sintetizam nas teorias sistêmicas. 


\section{A vida e sua organização: uma teoria para a vida}

A vida, o que é? Que leis regem sua compreensão? É possível um conhecimento científico sobre ela? Que tipo de biologia pode dar conta dos complexos processos da organização vivente? A compreensão da vida humana é necessariamente antropocêntrica, ou a dimensão humana da vida pode ser referida a algo para além de sua própria humanidade? O conhecimento da vida não pode parar onde começa (ou termina) a vida humana. A fronteira que separa o homo dos seres vivos não é natural: é uma fronteira cultural, que não anula a vida, mas a transforma e lhe permite novos desenvolvimentos (Morin, 1980).

Até o início da Idade Contemporânea, a biologia - ou o estudo da vida - estava fundamentada numa crença vitalista de que haveria uma força divina capaz de levar os organismos e seus respectivos processos biológicos à sua finalidade existencial. O sopro divino impregnava o corpo e esta alma, ou anima, colocava em ação a respiração, a digestão e o movimento dos seres animados. A descoberta do código genético, no início deste século, com a biologia molecular, foi determinante na reformulação dessa concepção, pois forneceu as bases para a noção da realização de um programa no desenrolar dos processos biológicos, não mais sob os auspícios de forças divinas, mas sob forças naturais. O programa inscrito no DNA, localizado em cada uma das células, determinaria não só o fato de que os processos biológicos fossem colocados em ação, mas também a forma e o ritmo que os mesmos tomariam em cada organismo particular. A genética veio trazer, com seus novos achados, a substituição da teleologia pela teleonomia.

Seja na concepção das forças divinas, na teleologia; ou das naturais, na teleonomia, a idéia que subjaz nos dois casos é a de um profundo determinismo. A vida funcionaria, em ambos, com objetivos e finalidades predeterminadas: ordem a partir da ordem, nada mais.

A ruptura com o determinismo é o primeiro e mais importante diferencial que uma nova teoria da vida vem inaugurar, através do conceito de auto-organização. Este supõe que a ordenação presente nos processos vitais emerge espontaneamente de uma desordem inicial. Do crescimento celular desordenado surgem a organização e a diferenciação precisas dos tecidos e dos órgãos. Do desorganiza- do aglomerado de enzimas nascem os sofisticados mecanismos de regulação e homeostase. Do excesso de microorganismos e toxinas acumulando-se na pele e nas mucosas aparece a imunidade, fornecendo adequadamente os limites e as aberturas de troca com o meio.

Se, por um lado, a existência do determinismo genético é inquestionável, a espontaneidade pode explicar a cura surpreendente de alguns doentes com câncer, a sobrevivência inesperada de algumas pessoas com graves traumatismos cranianos, ou a morte inconcebível de outras com simples pneumonias, por exemplo.

O paradoxo está lançado: condicionamento ou liberdade?

Deve-se a Schrödinger (1997), em meados do século passado, a primeira tentativa de associar essa aparente oposição entre espontaneidade e determinação. A hereditariedade ou informação genética - explicaria a ordem a partir da ordem e a termodinâmica dos sistemas abertos, a ordem a partir da desordem - sendo ambas faces do mesmo fenômeno de aptidão para a vida. Schneider e Kay (in Murphy \& O’Neill, 1997), na busca de uma explicação para essa relação entre ambos os princípios - explicação esta esboçada por Schrödinger -, acreditam hoje que o papel dos genes seria o de conter o processo auto-organizativo dentro das opções com maior probabilidade de sucesso para a sobrevivência.

Segundo alguns autores, seria a físico-química biológica, clássica ou não, englobando as noções da termodinâmica dos sistemas abertos, da teoria da informação e da cibernética, a epistemologia capaz de explicar o mundo vivo. Trata-se assim não de uma redução da vida à físico-química, mas de integrar as leis de organização físico-químicas que tornaram a vida possível a novas dimensões, em que os fenômenos do ser vivo encontrem seu lugar natural (Atlan, 1992) e de ampliar a físico-química para uma biofísica dos sistemas organizados (Atlan, 1992).

O conceito de auto-organização não surgiu, entretanto, da físico-química, mas sim da cibernética e do neo-mecanicismo, procurando explicar a organização dos seres vivos como máquinas cibernéticas com propriedades específicas (Atlan, 1992). Para alguns importantes autores dessa linha, como von Neuman, von Foerster e Ashby (in Capra, 1996; Prigogine I \& Stengers E, 1997), a auto-organização seria o princípio que explicaria os motivos pe- 
los quais os seres vivos, ao contrário das máquinas artificiais: a) mantêm um funcionamento global altamente confiável, que assegura a sobrevida, apesar de serem constituídos por elementos não confiáveis que se degradam continuamente; b) dispõem de um grande poder de criação, apesar do desgaste natural de seus componentes; c) funcionam com a maior parte de aleatoriedade, desordem e ruído, ou com os imprevistos.

Por tais razões, os únicos sistemas auto-organizadores conhecidos até hoje são as máquinas naturais. Esses sistemas, por sobreviverem a partir de sua abertura ao meio, são capazes de manter um estado de invariância fundamental, para além das transformações a que estão sujeitos nesta relação. Não há possibilidade lógica de auto-organização em um sistema fechado, sem trocas com o ambiente, como no caso das máquinas artificiais.

Auto-organização, portanto, é o fenômeno primário que caracteriza os seres vivos em sua organização tanto estrutural quanto funcional (Atlan, 1992). É o núcleo da complexidade biológica (Morin, 1996). É a emergência espontânea de novas estruturas e de novas formas de comportamento em sistemas abertos, que operam afastados do equilíbrio (Capra, 1996). É uma faculdade inconsciente que se situa em todas as células do organismo vivo, no nível de suas interações com os fatores aleatórios do meio ambiente (Atlan, 1992). É uma forma de inter-relações, existente no interior do organismo vivo que, além de mantê-lo vivo, estrutura-o, mas não depende da natureza física de seus componentes (Maturana \& Varela, 1995).

A faculdade de auto-organização leva o organismo inteiro a reagir aos fatores aleatórios, ou ruídos, não só tolerando-os, mas criando, através deles, complexidade, autonomia e adaptação. Em outras palavras, elaborando uma ordem cada vez mais diferenciada (Atlan, 1992).

A noção de ruído pode ser comparada à de entropia, advinda da termodinâmica dos sistemas abertos, ambas provenientes da teoria geral dos sistemas ou cibernética. Na teoria das informações, ruídos são erros na transmissão de mensagens, quaisquer perturbações que, ao interferirem na comunicação, degradam a mensagem, tornando-a errônea (Morin, 1996). Portanto, a concepção de ruído, quando aplicada às comunicações, ou mesmo ao código genético, exclui qualquer possibilidade de pensá-lo como um papel positivo e organizacio- nal. Transportando a definição para o campo da teoria dos sistemas, o ruído, ou erro de mensagem, ao contrário, vai propiciar uma multiplicação das vias de comunicação no sistema como um todo, para que este sobreviva aos erros de transmissão. Isso vai acarretar, para o sistema, um aumento tanto da sua complexidade, quanto da quantidade total de informação. Podemos dizer, em outras palavras, que o ruído tem, para os sistemas naturais, um papel positivo e constitutivo, sendo uma medida de sua complexidade.

A termodinâmica-não-linear parte do pressuposto de que os sistemas vivos, ao contrário dos sistemas artificiais, são sistemas abertos, vivem de sua abertura ao meio, alimentam-se do fluxo de matéria e energia que lhe vem do mundo exterior (Prigogine I \& Stengers E, 1997) e, por conta das flutuações internas causadas por esses fluxos da natureza, funcionam longe do equilíbrio. A constância dos processos biológicos é mantida com um certo grau de liberdade, dentro de limites de variação compatíveis com a preservação da vida.

De acordo com o segundo princípio da termodinâmica, nas reações de troca entre o sistema vivo e o meio há uma perda ou dissipação de energia, denominada entropia, resultante do movimento desordenado e aleatório das moléculas sob a ação do calor. Entropia é, portanto, uma medida de desordem molecular.

A desordem e a entropia serão tanto maiores quanto maior for o fluxo de matéria e de energia, ao qual os ecossistemas são sumamente sensíveis e abertos: Pela sua extrema abertura e pela sua extrema sensibilidade, os ecossistemas são extremamente vulneráveis aos agentes desorganizadores. Mas, também aqui, a fragilidade faz o vigor. São tão abertos uns para os outros, que se reorganizam e se alimentam mutuamente em caso de devastações (Morin, 1980).

Segundo Atlan (1992), a entropia é um dos grandes princípios físicos que regem a evolução dos sistemas naturais, pois, para sobreviver a ela, esse necessariamente deverá aumentar sua complexidade, com o objetivo de não dissipá-la, de torná-la utilizável e de ordenar o movimento das moléculas. Noutras palavras, transformará desordem em ordem, desorganização em organização. Sob tal aspecto, é possível estabelecer uma analogia com a teoria das informações de Shannon aplicada aos sistemas vivos, na qual o ruído pode acarretar me- 
lhores condições de sobrevivência e complexificação dos organismos, semelhante à ação e ao efeito da entropia sobre os mesmos.

Esses fluxos da natureza, de dimensão aleatória indiscutível, que nutrem os sistemas vivos, produzem entropia, desordem molecular e vida. Em outras palavras, a vida se nutre da entropia, da desordem, do acaso e dos fluxos que, levando os sistemas vivos a pontos críticos de instabilidade, viabilizam o emergir de um alto grau de ordem.

Os sistemas vivos, portanto, em sua complexidade organizacional e em seu dinâmico desenvolvimento auto-organizador, criam informação, organização e ordem não apesar do ruído, do aleatório, da entropia e da desordem, mas a partir dos mesmos, que se sucedem ininterruptamente. Poderíamos ir mais além e dizer que a solução complexa do ser vivo é acentuar e ampliar a desordem, para dela extrair a renovação de sua ordem (Morin, 1997). Autoorganização é, por isso, auto-reorganização, segundo o referido autor.

O ruído, o aleatório e a desordem, outrossim, resultam de acoplamentos estruturais nos quais duas ou mais estruturas, a partir da interação que estabelecem entre si, representam fontes recíprocas de perturbação e transformação. As mudanças desencadeadas por esta interação, assim como os efeitos do ruído, do aleatório e da desordem, seguem o sentido da vida se forem compatíveis com a preservação da auto-organização e da morte, em caso contrário (Maturana \& Varela, 1995).

A expressão acoplamento estrutural, utilizada por Maturana \& Varela (1995), é outra forma de representar a interação absolutamente necessária entre o ser vivo e o ecossistema, em que ambos são modificados um pelo outro. Por esse motivo é que, para Morin, autoorganização é também eco-organização pois, para organizar-se, mesmo que arriscando-se à desintegração, "a vida tem uma necessidade vital da vida” (Morin, 1980). Prigogine e Stengers também acreditam nessa premissa, pois ambos observaram no mundo físico-químico que as células são parte integrante do mundo que as nutre, constituem uma espécie de encarnação dos fluxos que elas não cessam de transformar: (...) Se separadas de seu meio, morrem rapidamente (Prigogine I \& Stengers E, 1997).

A vida é, portanto, uma auto-eco-organização pois, ao mesmo tempo em que preserva sua integridade e seus limites, o faz construindo espaços de abertura e de trocas com o meio.
Pensando desse modo, em que a interação do ser vivo com o ecossistema, em sua dupla dimensão física e viva, é absolutamente necessária à sua sobrevivência, é preciso compreender de que forma se estabelecem as interdependências e as inter-retroações entre um e outro.

O conceito de auto-organização está estreitamente vinculado ao pensamento da complexidade o qual, ainda que sendo hoje um desafio, tende para o conhecimento multidimensional e para a retomada da riqueza e movimento dos fenômenos que ele busca conhecer.

A complexidade - ou riqueza biológica dos sistemas vivos - aumenta com o número e a diversidade dos elementos que compõem o sistema e com a flexibilidade e a indeterminação das inter-relações presentes no mesmo. Traduz-se por uma aptidão para criar formas e estruturas novas, ou seja, qualidades auto-organizadoras, a partir da incerteza, da aleatoriedade, da desordem, do ruído: os sistemas mais complexos são estruturas de acolhimento cada vez mais abertas à novidade e cada vez mais sensíveis a ela (Morin, 1996).

A auto-organização e a complexidade estão também estreitamente relacionadas à autonomia. Essa pode ser conceitualizada como a possibilidade de um sistema aberto, utilizando as causalidades externas em benefício próprio, não submergir a elas, mas, ao contrário, emancipar-se delas, mantendo seu meio interno constante, em equilíbrio dinâmico, por meio de mecanismos de retroação e feedback. A autonomia é também uma propriedade emergente. Decorre da própria complexidade organizacional do sistema vivo como um todo. Não é predeterminada pelo código genético e não existe nos seus componentes isoladamente. Mas ao mesmo tempo em que ganha uma progressiva autonomia no desenrolar de sua história, o sistema vivo passa por situação paradoxal: torna-se mais dependente do meio externo, de onde extrai matéria, energia e informação. Noutras palavras, quanto mais um sistema desenvolver sua complexidade, mais poderá desenvolver sua autonomia e mais dependências múltiplas terá (Morin, 1996). Complexidade e autonomia são conceitos indissoluvelmente ligados ao de individualidade nos sistemas vivos: $A$ individualidade molecular do organismo (identidade) é condicionada pelos encontros parcialmente aleatórios com estruturas moleculares e celulares trazidas por um ambiente sempre renovado, ao menos em parte (Atlan, 1992). 
Autonomia, individualidade e identidade são algumas das características dos sistemas auto-organizados. A auto-organização e a complexidade do ser vivo são também responsáveis por sua adaptatividade, isto é, sua aptidão para adaptar-se e readaptar-se em diversas condições e diferentes meios. $\mathrm{Ou}$, em outras palavras, uma adaptação às novidades, riscos e mudanças oferecidos pela eco-organização, e cuja flexibilidade adaptativa se expressa por estratégias inventivas e diversificadas que vêm substituir os comportamentos rígidos (Morin, 1980). Segundo Maturana, é o fenômeno do acoplamento estrutural, com as histórias de mudanças estruturais que o acompanham, o responsável pela conservação da adaptação dos sistemas auto-organizados (Maturana, 1997). A auto-organização, a complexidade e este comportamento adaptativo são também uma medida de autonomia e decorrem do aumento da quantidade total de informações contida no sistema, das multiplicadas e numerosas interconexões conseqüentes, que por sua vez ocasionam uma variedade maior de respostas desse sistema aos estímulos diversificados e imprevisíveis provenientes do ambiente: Num ambiente que seja fonte de agressões imprevisíveis, a variedade na estrutura e nas funções do sistema é um fator indispensável de autonomia (Atlan, 1992).

Uma relação entre esse conceito de adaptatividade pode ser estabelecida com o de aprendizagem não dirigida. Segundo Atlan (1992), esse tipo de aprendizagem é próprio dos sistemas auto-organizadores, nos quais os padrões de comportamento, ao emergirem da interação mais primária do organismo com os estímulos aleatórios ambientais, tornam-se padrões inventados. Com esse tipo de aprendizagem o caráter indiferenciado do sistema diminui; a variedade, a heterogeneidade, a especificidade e a diferenciação dos padrões aprendidos aumentam. E esses padrões aprendidos terminam por funcionar como estímulos internos aleatórios, realimentando todo o processo, favorecendo a complexidade, a autonomia e a adaptação.

Mas como interagimos com o meio ambiente, nós, humanos, que ao processo do aprendizado e do conhecimento introduzimos a racionalidade, a reflexão, a emoção, a consciência e o inconsciente, em síntese, a cultura? Como se constitui e se expressa a "vida do espírito" na vida humana?

Pudemos constatar no início deste texto que o conceito de auto-organização veio rom- per com o finalismo/determinismo implícito tanto na teleologia quanto na teleonomia, dando lugar à idéia de uma criação espontânea de organização no interior da desordem inicial dos processos vitais. No entanto, ao considerá-los especificamente na existência humana, razão, emoção, consciência e sobretudo intenções, projetos e finalidade são questões que emergem em primeiro plano. Há escolhas? Há um querer? Há um ser humano dotado de intenções que atribui fins a si próprio? Ou a única finalidade racionalmente aceitável é a de um mecanismo otimizado e não a intenção resultante de uma vontade livre?

A construção teórica de Atlan sobre essas questões é no mínimo instigante. Naturalmente a auto-organização como essência da vida é considerada por ele como o fenômeno primordial dos mecanismos do verdadeiro querer, o qual é inconsciente, e se situa em todas as nossas células, no nível, muito precisamente, de suas interações com todos os fatores aleatórios do ambiente (Atlan, 1992), orientando o nosso viver, que parece sempre se dar apesar e através de nós. O querer inconsciente, conjunto dos mecanismos pelos quais nosso organismo inteiro reage ao aleatório e à novidade, é o fenômeno primário que caracteriza tanto nossa organização estrutural quanto funcional (Atlan, 1992).

Esse querer inconsciente corresponderia à alma vegetativa dos antigos - compreendida como o conjunto de aparelhos que assegura as funções fisiológicas e metabólicas características de qualquer organismo vivo - modulada pela alma animal, ou sistema dos afetos; e pela alma inteligente, ou aparelho cognitivo. A intuição primeira de nosso corpo e de nosso meio biológico ocuparia um caráter central e de partida na construção de uma intencionalidade: com sua respiração, alimentação, sensibilidade e motricidade reflexas; sua sensibilidade inconsciente e difusa; sua percepção imediata e indivisa do prazer e da dor; sua consciência pré-lingüística. Essa intuição seria alargada pelos afetos cada vez mais diferenciados, expressos principalmente pela linguagem pré-lingüística, e finalmente pela razão, apoiada na medida das possibilidades, na verificação, na linguagem falada e na palavra humana, para a elaboração e realização dessa intencionalidade (Atlan,1991; 1992).

A consciência seria, para Atlan, a memória se manifestando. Diz respeito ao passado, pois é uma presença do conhecido quer se tra- 
te de um conhecido de maneira perceptiva, intelectual, instintiva, direta, indireta, clara ou nitida, vaga ou pouco diferenciada, formulada ou não formulada (Atlan, 1992). A interação entre o passado e o futuro, entre o consciente e o inconsciente, entre a memória e o querer, é o que geraria os fenômenos híbridos e secundários, principalmente o desejo consciente. Esse desejo seria a exibição, como memória, desses processos auto-organizadores originados do querer inconsciente e nascidos da vida vegetativa, acrescidos à consciência voluntária que, por mecanismos de armazenagem dos processos auto-organizadores efetivamente vividos, interviriam secundariamente, decidindo sobre a resposta a um estímulo.

É importante considerar que o funcionamento desses fenômenos híbridos deve acontecer como um compromisso ótimo e flexível entre a memória e o querer. Para Atlan, o delírio não seria o imaginário projetado no real, mas a conservação demasiadamente sistemática e demasiadamente rígida de estados de auto-organização que, normalmente, deveriam se suceder, modificando-se (Atlan, 1992).

A racionalidade, como busca da verdade, ao invés de se firmar na ciência, deveria se fundar no sistema dos afetos e na vida vegetativa de cada indivíduo em sua relação com o meio social, em uma memorização flexível, abrindo-lhe o mundo infinito das possibilidades.

Nesse sentido, não se pode conceber o indivíduo como a simples realização de um programa determinado geneticamente, sem vontade livre, ou como apenas uma "pessoa potencial”. Segundo Atlan o indivíduo não está contido em potencial mesmo no ovo fecundado, sob a forma da totalidade de suas propriedades, que existiriam já como potencialidades reprimidas, esperando uma ocasião para se exprimir. Falta-lhe o que resultará das interações com o meio, daquilo a que chamamos o desenvolvimento epigenético. (...) Ora, existem, de fato, potencialidades de desenvolvimento em um ovo fecundado, mas sua extensão varia, ela própria, ao longo do desenvolvimento (Atlan, 1991).

Além disso, as experiências de transplantes de frações de órgãos inter-espécies, em laboratório, nos mostram que a vida é possível em outras condições e que, certamente, o embrião humano traz em si outras potencialidades que não as especificamente humanas. Maiores que a de um indivíduo humano e necessariamente maiores que as de uma pessoa humana. Ou seja, o desenvolvimento embrio- nário consiste não apenas em exprimir potencialidades, mas também em reduzir potencialidades, para as limitar às de um ser humano (Atlan, 1991).

Em síntese, o processo de organização e de auto-organização da vida tem as bases em três sistemas abertos: o ecossistema, o biológico e o social, numa interação contínua e permanente de formas provisórias de expressão. Os seres vivos nascem, se desenvolvem e se mantêm em constante interação com o meio, que os atravessa incessantemente com fluxos, forças e ruídos. Nada é estático, nada é imutável. Porque é da comunicação entre esses três cenários que nossa identidade recebe influxo, nosso caráter se forja numa escolha entre múltiplas possibilidades e nossa história se constrói. Por outro lado, quanto mais os sistemas social, biológico e ecológico se comunicam a partir de suas diferenças, mais ricos e mais complexos cada um deles se torna, permitindo infinitas combinações de vida. Pela influência do meio, o sistema vivo está constantemente se desorganizando, se desordenando, se desintegrando, vivendo uma série de pequenas e fugazes mortes cotidianas. As enzimas se degradam, os metabólitos são eliminados, os líquidos evaporam, $90 \%$ de suas moléculas envelhecem e morrem no espaço de um ano (Guyton, 1996).

Apesar da degeneratividade de seus componentes e das agressões do meio ambiente, o organismo é capaz de, complexificando-se, extrair desses eventos, princípios de ordem interna, ordenando-se e ordenando ativamente o meio para assegurar sua sobrevivência. É evidente, portanto, que o morrer faz parte do viver e que, indo mais além, a morte é, ela mesma, fonte de vida. As atitudes diante da morte ao longo da história e através das culturas, bem como as descobertas mais recentes da teoria da auto-organização, corroboram essas afirmativas.

E então, se o organismo se mantém, simultaneamente, tanto sob o efeito da degeneratividade causada por um meio perturbador, quanto da sua capacidade de se adaptar e de adaptar esse meio a seus próprios fins, o que falha quando o organismo se encaminha para a morte real? Como explicar a morte de seres que, convivendo intimamente com a mortalidade, possuem uma aptidão inata para a vida? 


\section{O exemplo da morte infantil}

A abertura e a sensibilidade aos fluxos ambientais são características inerentes ao sistema vivo, às quais, quanto mais intensas, melhores chances de sobrevivência lhe oferecem. Somente um motivo como esse poderia explicar o fato de que seres tão abertos, tão desprotegidos, tão sensíveis e tão vulneráveis como os bebês, sobrevivam, em maioria.

Esta constatação é, no entanto, paradoxal, pois as crianças muito pequenas estão, na mesma medida, extremamente sujeitas à morte. Diferentes dos adultos, são muito mais suscetíveis à inanição, à desidratação, à obstrução respiratória, à aspiração de alimentos, aos acidentes domésticos e às várias formas de abandono, de negligência e de maus-tratos.

A grande surpresa e interrogação não é, portanto, com relação à sua morte, mas o fato de conseguirem sobreviver, apesar de todos os riscos e circunstâncias adversas. A vida seria o acontecimento dos mais improváveis para os bebês, dada a imensa vulnerabilidade, na qual estão profunda e completamente imersos. Para fazer frente a este desafio de viver em meio a perturbadores acontecimentos como o frio, a fome ou a sede, a criança pequena conta, dentro de si, apenas com uma faculdade inconsciente - intuitiva, corporal, somática - inscrita em suas células, que lhe garante um sentido global de auto-conservação. Para que sobreviva, tendo em vista tal fragilidade, é preciso um meio ambiente capaz de oferecer a seus processos biológicos e a este seu sentido global de auto-conservação, não só substratos e fluxos, mas fundamentalmente barreiras, filtros e proteção.

Winnicott (1995) foi o autor que, compreendendo a vulnerabilidade infantil, melhor estabeleceu correlações entre a proteção ambiental e a sobrevivência saudável dos bebês. Para ele, a mãe biológica ou substituta é a representante desse tipo de ambiente, cujas funções protetoras e propiciadoras, ela exerce através de cuidados predominantemente corporais, aos quais alia uma afetividade íntima e sintonizada com seu bem-estar.

A forte união psicobiológica entre a mãe e o bebê assegura um fluxo adequado de energia e um mínimo de desordens e de ruídos em seu cotidiano. Essa é a única forma de lhe proporcionar maiores probabilidades de emergência espontânea de organização, de ordenação, de saúde e de sobrevida.
As manifestações dessa organização ocorrem na "alma vegetativa", nas funções metabólicas básicas, no psicossoma dos bebês. Dentre essas funções, destacam-se a respiração, a alimentação, a motricidade e a sensibilidade reflexas, a sensibilidade inconsciente e difusa, a percepção indivisa de prazer e dor, a indiferenciação afetiva e a consciência pré-lingüística.

Seu bom funcionamento somático e psíquico traduz a adequação entre os cuidados oferecidos por seu ambiente protetor e propiciador e as suas reais necessidades. Traduz também um relacionamento benéfico com as desordens, os imprevistos e as invasões provenientes tanto do meio externo quanto de seu próprio interior. Ou seja, constrói uma boa imunidade que mantém seu meio interno dentro de variações compatíveis com a vida.

O mecanismo explicativo para o adoecimento dos bebês em Winnicott (1978) é bastante interessante, e pode incluir a própria teoria da auto-organização. Quando há uma invasão excessiva de desordens ambientais, em geral por falha na proteção materna, o psicossoma do bebê tem duas alternativas. Ou metaboliza essa desordem e evolui em autonomia, em complexidade e em desenvolvimento; ou sucumbe à mesma e dissocia a psique do soma, adoecendo. A essa dissociação se segue o fato de que ambas as dimensões do sistema vivo ficam impossibilitadas de se alimentarem e de interagirem, enfraquecendo-se e tornando-se mais vulnerável a distúrbios tanto somáticos quanto psíquicos. Quadros orgânicos leves foram observados freqüentemente por Winnicott (1994) em sua clínica pediátrica, como a enurese, a constipação intestinal, a asma brônquica, os resfriados, as enxaquecas. Spitz (1998) refere que esses quadros podem assumir feições extremamente graves, como o marasmo, a morte "acidental", o infanticídio, entre outras.

Dada a vulnerabilidade natural do bebê, a atitude de quem dele cuida é sempre responsável, em algum grau, pelo desenrolar de cada uma das possibilidades apresentadas: de adoecimento ou de saúde. O resultado final vai depender da correlação entre a força invasiva do ambiente e o quantum de desordens cada bebê é capaz de metabolizar e transformar em complexidade de vida.

As funções maternas de proteção e cuidado são exercidas principalmente a partir de um estado psicobiológico especial alcançado pela mãe no final da gestação - denominado 
preocupação materna primária - que a torna capaz de sintonizar e de suprir as necessidades de seu bebê. Apesar de referidas à biologia da gestação, e supondo que seja a própria mãe biológica quem cuide do bebê, tais funções só serão adequadamente exercidas se a mãe estiver "pessoalmente bem".

Para que possa estar intensamente atenta e cuidadosa com seu bebê, a mãe biológica permanece num estado altamente vulnerável que, se rompido, pode levá-la a exercer aquelas funções com dificuldades, ou com muitas falhas. Isso, por sua vez, pode desencadear a já descrita dissociação psicossoma no bebê e os diversos estados possíveis de enfermidade (Winnicott, 1990).

Se a função da mãe é proteger diretamente o bebê, cabe à família proteger a mulher nesse momento altamente exigente que os primeiros tempos da criança representam para ela. Essa proteção deve ser também psicobiológica - como o vínculo que estabelece com o bebê - e é representado concretamente pelo suprimento de suas necessidades alimentares, de repouso, de ar puro, de higiene, de carinho, de segurança e de valorização, entre outros. Um ambiente que garanta bem-estar à mulher para que a mãe possa despontar e brilhar com tranqüilidade para seu bebê: esse é o papel da família na sobrevivência da criança pequena. Marido, companheiro, filhos, irmãos, tios, pais, avós, padrinhos, agregados, amigos íntimos, a possibilidade de "famílias" é quase infinita. Quanto mais próxima a pessoa, mais importância nessa função.

As redes sociais de intercâmbio e de ajuda mútua estão por nós incluídas nessa categoria ampliada de família, pois são construídas através dos laços de parentesco, de vizinhança e de amizade. Representam, principalmente para os núcleos de mais baixa renda, um insubstituível recurso nos momentos de crise e viabilizam, inclusive, um maior acesso aos bens e serviços comunitários e públicos disponíveis para evitar as doenças e as mortes das crianças.

A construção e o grau de conectividade dessas redes depende, em última instância, da capacidade que os membros da família possuam, em sua dinâmica relacional, para tecer elos com um círculo social mais vasto. Estruturas disfuncionais e processos rígidos dessa dinâmica, normalmente, acarretam uma pobreza nos laços sociais de ajuda, o que se traduz em comportamentos familiares de grande vulnerabilidade e desproteção para a mãe e a criança. A mulher é atingida principalmente por: situações de cargas diferenciais de responsabilidade no cotidiano, necessidade de trabalho feminino fora do lar, ausência de apoio nas tarefas domésticas, carência de satisfações básicas, incerteza existencial, irresponsabilidade, reprovações, insultos, agressividade, desavenças, disputas crônicas com a família de origem, alcoolismo, violência doméstica, descontinuidade nas relações familiares ou isolamento social.

Através da figura materna assim atingida, a família pode ser hostil à criança de variadas formas: falta de atenção, cuidado e proteção inadequados; falta de satisfação das necessidades básicas de nutrição, higiene, saúde e aprendizagem; abandono parcial ou total; carência afetiva ou, em graus extremos, agressões.

Pela ausência de uma rede social de apoio, essas famílias tendem a se submergir às forças e aos acontecimentos desorganizadores do meio ambiente, não sendo capazes de utilizá-los em benefício de sua própria evolução, diferenciação e complexificação de suas experiências.

Ao não estar inserido em uma rede de dependências múltiplas, benéficas e construtivas, o bebê fica privado da proteção necessária ao seu desenvolvimento. Graus excessivos de desordem ambiental invadem seu organismo. Rompe-se a unidade de seu psicossoma, tornando-o presa fácil de doenças. Estando doente, provavelmente não contará com os cuidados necessários para sua recuperação.

Em síntese, não existe, em geral, uma determinação nem da vida e nem da morte, nem da inteligência, nem do sucesso e nem do fracasso. A história mostra trajetórias de pessoas que nasceram em condições totalmente desfavoráveis e conseguiram, a partir da desordem e do ruído construir sua expressão social. Existe sim, um ponto de partida específico onde cada um tem a sua vantagem comparativa entre o que é determinado pela hereditariedade e a espontaneidade das interações, entre o peso dos fatores biológicos e os condicionantes emocionais e sociais. E onde o excesso de ruído, de instabilidade e de desproteção pode ser fatal. 


\section{Referências bibliográficas}

Ariés P 1988. Sobre a história da morte no Ocidente desde a Idade Média. Teorema, Lisboa.

Atlan H 1991. Tudo, não, talvez: educação e verdade. Instituto Piaget, Lisboa.

Atlan H 1992. Entre o cristal e a fumaça: ensaio sobre a organização do ser vivo. Jorge Zahar, Rio de Janeiro.

Bertalanffy LVY et al. 1987. Tendencias en la teoría general de sistemas. Aliaza Editorial, Madri.

Bott E 1976. Família e rede social. Francisco Alves, Rio de Janeiro.

Bronfmann M 2000. Como se vive se muere: familia, redes sociales y muerte infantil. Cuernavaca, México.

Capra F 1996. A teia da vida: uma nova compreensão dos sistemas vivos. Cultrix, São Paulo.

Guyton H \& HALL G 1996 Textbook of medical physiology. Saunders Company, Filadélfia.

Hoffmann LMA 1991. Os médicos e a morte na infância: a representação de um tema interditado. Dissertação de mestrado. Instituto Fernandes Figueira, Fundação Oswaldo Cruz, Rio de Janeiro, 123pp.

Jacob F 1985. A lógica da vida: uma história da hereditariedade. Graal, Rio de Janeiro.

Kovács MJ (org.) 1992. Morte e desenvolvimento humano. Casa do Psicólogo, São Paulo.

Lovelock JE 1987. Gaia: um novo olhar sobre a vida na terra. Ed. 70, Lisboa.

Maturana H 1997. A ontologia da realidade. Ed. UFMG, Belo Horizonte.

Maturana H 1998. Da biologia à psicologia. Artes Médicas, Porto Alegre.

Maturana HE e Varela FG 1995. A árvore do conhecimento. Editorial Psi, São Paulo.

Moigne JL 2000. A inteligência da complexidade. Peirópolis, São Paulo.

Morin E 1980. O método II: a vida da vida. Publicações Europa-América, Portugal.
Morin E 1996. Ciência com consciência. Bertrand Brasil, Rio de Janeiro.

Murphy MP \& O’Neill LAJ (org.) 1997. O que é vida? 50 anos depois: especulações sobre o futuro da biologia. UNESP, São Paulo.

Prigogine I \& Stengers E 1997. A nova aliança. Ed. UnB, Brasília.

Prigogine I 1996. O fim das certezas: tempo, caos e as leis da Natureza. Ed. UNESP, São Paulo.

Rodrigues JC 1983. O tabu da morte. Achiamé, Rio de Janeiro.

Roitt I et al. 1999. Imunologia. Ed. Manole, São Paulo.

Sacks O 1997. Um antropólogo em Marte. Companhia das Letras, São Paulo.

Schrödinger E 1997. O que é a vida? O aspecto físico da célula viva. Ed. UNESP, São Paulo.

Shorter E 1975. A formação da família moderna. Terramar, Lisboa.

Spitz R 1998. O primeiro ano de vida. Martins Fontes, São Paulo.

Vaitsman J 1994. Flexíveis e plurais: identidade, casamento e família em circunstâncias pós-modernas. Rocco, Rio de Janeiro.

Vaz NM \& Faria AMC 1993. Guia incompleto de imunologia. Coopmed, Belo Horizonte.

Velho GE \& Figueira SA 1981. Família, psicologia e sociedade. Campus, Rio de Janeiro.

Winnicott DW 1978. Da pediatria à psicanálise. Francisco Alves, Rio de Janeiro.

Winnicott DW 1990. Natureza humana. Imago, Rio de Janeiro.

Winnicott DW 1994. Explorações psicanaliticas. Artes Médicas, Porto Alegre.

Winnicott DW 1995. A família e o desenvolvimento individual. Martins Fontes, São Paulo. 